\title{
Development of new approaches to the study of pitting corrosion resistance of stainless steels obtained by selective laser melting
}

\author{
Olga Parmenova*, Svetlana Mushnikova, Vitaliy Bobyr, and Evgeniy Samodelkin \\ NRC "Kurchatov Institute" - CRISM "Prometey", 191015 St. Petersburg, 49 Spalernaya str., Russia
}

\begin{abstract}
This paper presents the results of comparative corrosion resistance studies of stainless steels manufactured by selective laser melting (SLM) in the initial state with subsequent heat treatment and machining. Pitting corrosion tests are carried out, according to ASTM G48 method A in $10 \% \mathrm{FeCl}_{3} \cdot 6 \mathrm{H}_{2} \mathrm{O}$ solution at elevated temperature and exposure time for $5 \mathrm{~h}$. The studies were performed on the AISI 321 and AISI $316 \mathrm{~L}$ stainless steels manufactured by SLM. It was obtained that laser scanning speed decrease led to density rise by other SLM parameters being equal. Porosity affected to the stainless steel corrosion behaviour significant. Metal density decrease resulted to corrosion rate rise. Microstructure examination showed that pitting corrosion development depended on surface steel condition.
\end{abstract}

\section{Introduce}

The advantages of using additive technologies, including selective laser melting (SLM), are due to the possibility of small-scale production of compound configuration products with closed inner cavities without additional processing and technological operations (manufacturing foundry equipment, milling, etc.). The stainless steels powder development determines the opportunities for obtaining pipeline fittings for the shipbuilding, chemical and oil and gas industries SLM products. Obviously, it is necessary to ensure high corrosion resistance with the complex of mechanical properties of the SLM-materials for these applications.

It is well-known that stainless steels are susceptible to pitting corrosion in chloride solutions like sea water. There is a number of standards to evaluate corrosion behavior including cyclic potentiodynamic polarization measurements, immersion-test in various corrosion environment $\left(3,5 \%\right.$ or $\left.5 \% \mathrm{NaCl}, 10 \% \mathrm{FeCl}_{3} \cdot 6 \mathrm{H}_{2} \mathrm{O}\right)$ at different temperature and time exposition, $5 \%$ aqueous $\mathrm{NaCl}$ salt spray testing. These test methods allow to ranking corrosion resistance level of cast and wrought stainless steels. The standards, such as DNV-OS-F101, STO Gazprom 2-3.7-050, GOST R 54382, suggest the requirements to marine stainless steel use including mass loss limits and pits absence $[1,2]$.

SL-melted metal is characterized developed surface and porosity. It is known that condition of the steel surface affects adverse on corrosion resistance because of heterogeneity and microcrevice presence. Therefore, suggested corrosion resistance evaluation can be inapplicable, in particular pores and inclusions are difficult to recognize.

The aim of this research was to evaluate pitting corrosion resistance of SL-melted stainless steel using microstructure examination with $3 \mathrm{D}$ corrosion damage study.

\section{Experimental}

\subsection{Materials}

The samples were carried out by melting powders of AISI 321 (Polema OJSC, Russia) and AISI 316L (Höganäs JSC, Sweden) austenitic stainless steels. Corrosion test specimens 3 or 5 by 25 by $50 \mathrm{~mm}$ were made in nitrogen atmosphere by EOSintM270. The thickness of initial state samples was equal $3 \mathrm{~mm}$, whereas undergoing following surface or heat treatment specimens were $5 \mathrm{~mm}$ in thickness. Specimens were formed at laser beam power of $190 \mathrm{~W}$, scanning speed was equal $600,650,750 \mathrm{~mm} / \mathrm{s}$ (AISI 321) and $800 \mathrm{~mm} / \mathrm{s}$ (AISI 316L). By specimens forming outer layer remelting was used. For each laser beam scanning speed 3 specimens were formed.

The chemical composition (in wt.\%) of AISI 321 and AISI 316L stainless steels obtained by SLM is C- 0.07, Ni-10.6, Cr-17.2, Si-0.8, Mn-0.8, Ti-0.8 and C- 0.03 , Ni13.3, Cr-16.8, Mo-2.6, Mn-1.5, respectively.

\subsection{Heat treatment and machining}

Corrosion properties were studied on the austenitic SLM stainless steels in 3 conditions: A - after SLM (initial state); B - after machining; C - after heat treatment (austenitization) and machining. Austenitization was carried out at $1100-1150^{\circ} \mathrm{C}$ for 30 $\min$ and then specimens were water quenched. 


\subsection{Surface investigation}

The surface topography investigation was carried out by Olympus LEXT 4100. The study was done on the specimens before and after corrosion tests.

Surface roughness was measured by profilometer (Hommel Etamic).

\subsection{Corrosion test}

The pitting corrosion resistance of SLM steels was studied according to ASTM G48 method A. Before test the sample dimensions were measured and then total surface area was calculated. Specimens were cleaned by acetone and air-dried. Each specimen was weighed accurate within $0.0001 \mathrm{~g}$.

The test specimens were immersed in $10 \%$ $\mathrm{FeCl}_{3} \cdot 6 \mathrm{H}_{2} \mathrm{O}$ at $60^{\circ} \mathrm{C}$ for $5 \mathrm{~h}$. Following testing, specimens were rinsed in distilled water, then in acetone. The clean procedure was repeated twice and then specimens were air-dried.

\subsection{Microstructure research}

Microstructure studies were carried out on corrosion test specimens. Samples were polished according to standard metallographic procedure and following electrochemical etching was carried out in a $10 \%$ water solution oxalic acid.

The SLM steels porosity was evaluating by gravimetric method and by microstructure research.

\section{Results and discussion}

\subsection{Pitting corrosion rate study}

Figure 1 shows corrosion rate of both SL-melted austenitic stainless steels. It should be noticed treatment has a different influence on corrosion resistance of AISI 321 and AISI 316L. Surface machining of SL-melted AISI $316 \mathrm{~L}$ obtained by $800 \mathrm{~mm} / \mathrm{s}$ results to corrosion loss increasing by $3 \%$. Heat treatment and following machining using improve corrosion behaviour comparison with condition A by $20 \%$.

AISI 321 corrosion resistance is differed and depends on the scanning speed. Corrosion rate of specimen B is reduced especially for samples obtained by 600 and 650 $\mathrm{mm} / \mathrm{s}$ by 10 and $13 \%$ respectively. Austenitization promotes corrosion susceptibility decrease of specimen C obtained by $600 \mathrm{~mm} / \mathrm{s}$ by $12 \%$ as opposed to SLmelted steels produced by 650 and $750 \mathrm{~mm} / \mathrm{s}$. These correlations don't conform to conception of machining and positive influence of heat treatment, therefore microstructure and porosity study are carried out.

\subsection{Surface and porosity research}

Figure 2 shows microstructure of SL-melted AISI 321 steel in initial state and after different treatment.

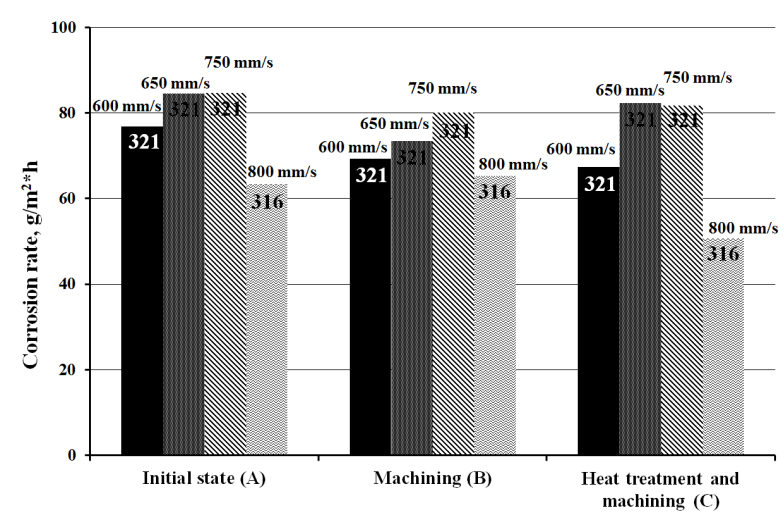

Fig. 1. Treatment influence on corrosion rate of SL-melted AISI 321 (scanning speed $-600,650,750 \mathrm{~mm} / \mathrm{s}$ ) and AISI $316 \mathrm{~L}$ (scanning speed $-800 \mathrm{~mm} / \mathrm{s}$ ) in $10 \% \mathrm{FeCl}_{3} \cdot 6 \mathrm{H}_{2} \mathrm{O}$ at $60^{\circ} \mathrm{C}$ for $5 \mathrm{~h}$

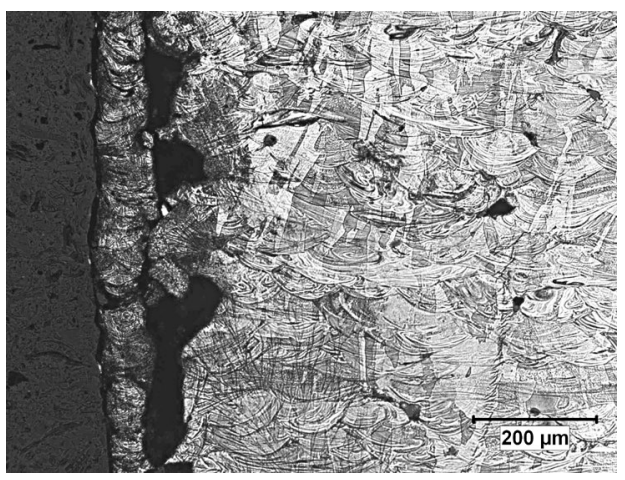

a)

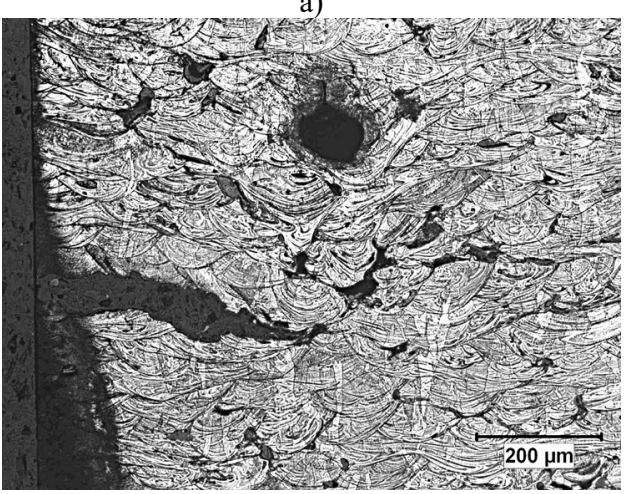

b)

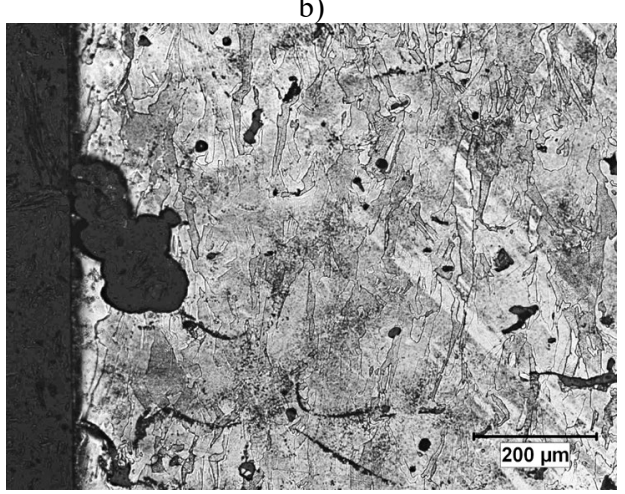

c)

Fig. 2. Microstructure of SL-melted AISI 321 stainless steel obtained by $650 \mathrm{~mm} / \mathrm{s}$ after corrosion test in $10 \%$ $\mathrm{FeCl}_{3} \cdot 6 \mathrm{H}_{2} \mathrm{O}$ at $60^{\circ} \mathrm{C}$ for $5 \mathrm{~h}$ : a) initial state (A); b) machining (B); c) austenitization and machining (C) 
It can be seen, that SL-melted steel structure has laser tracks and a skin on the surface (fig. 2 a). The skin is formed by outer layer re-melting. Pores, cracks and nonmetallic inclusions are observed in the metal bulk. Heat treatment removes tracks and elongation grain is observed (fig. 2 c).

The pores occur between tracks and their amount rises with scanning speed increasing. For example, porosity of specimens AISI 321 obtained by 600, 650 and $750 \mathrm{~mm} / \mathrm{s}$ is equal 2, 2.3 and $3.5 \%$, respectively (fig. 3). Manufactured by $800 \mathrm{~mm} / \mathrm{s}$ AISI $316 \mathrm{~L}$ specimens have the largest pore amount by $4.1 \%$. Porosity increasing was obtained by laser scanning speed rise other parameters being equal [3].

Figure 4 shows sample surface view of SL-melted steel in different conditions prior corrosion test. Initial state (A) surface distinguishes significant altitude difference (fig. 4 a), which can reduce corrosion resistance. The specimen roughness is measured: $R_{a}$ is equal $5-6 \mu \mathrm{m}, \mathrm{R}_{\mathrm{z}}$ is the size of $24-29 \mu \mathrm{m}$. Outer layer removing by machining (B) leads to pores opening (fig. 4 b). Meanwhile roughness values reduce significant: $R_{a}$ $=0.09 \mu \mathrm{m}, \mathrm{R}_{\mathrm{z}}=0.89 \mu \mathrm{m}$. Defects occur on the sample C surface where oxide scale is removed difficult (fig. $4 \mathrm{c}$ ). The roughness of sample $C$ rises a few: $R_{a}=0.14 \mu \mathrm{m}, R_{z}$ $=1.18 \mu \mathrm{m}$. The high polish degree can lead to surface cold work hardening of austenitic stainless steels. The surface cold working and oxide scale presence affect to corrosion resistance negative.

\subsection{Pitting propagation study}

Pitting propagation according to surface condition is presented on the figure 2. As has been mentioned sample A has a full-density outer layer which is equal $80 \mu \mathrm{m}$. Surface defects presence, high value roughness results to initial local pits that growth through outer re-melted zone which forms full-density layer (fig. 2 a). Further pit propagation occurs under outer layer and subsurface pitting corrosion developments. Growing through remelting layer pit can combine with pore. In this case corrosion products are hard to remove from the pore and oxygen is excluded inside pore since melting was carried out in an inert atmosphere. This leads to increase mass loss because of corrosion products hydrolysis. On the other hand, passive film can absent on the pore surface due to SLM process feature. Corrosion damage is significant, and locates along the working area.

Outer layer removing (specimen B) leads to pits grow deep specimen. Prefer sites for pitting corrosion initiation are boundary between tracks, opening pores, cracks. Corrosion damage propagation occurs in the normal direction along tracks of growing the sample (fig. 2 b). Austenitization (specimen C) results to pits development through grain (fig. 2 c).

\subsection{Discussion}

Corrosion resistance of stainless steels obtained by SLM reducing is explained by pores presence [4-6], segregation, cast structure or residual stresses [4, 6-9].

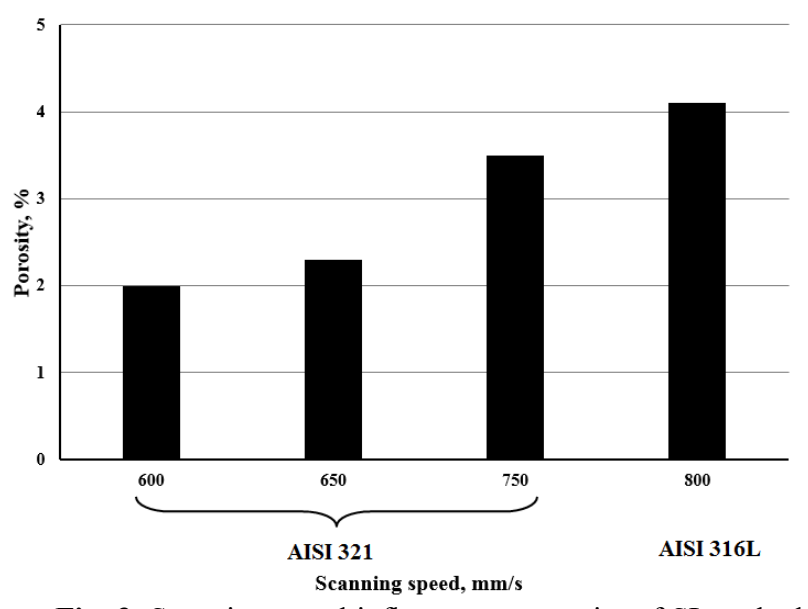

Fig. 3. Scanning speed influence on porosity of SL-melted stainless steels

Meanwhile the pores influence the most effect on corrosion damage. Process parameters (laser scanning speed, power, spot size diameter, hatch distance, powder layer thickness) impact on the material density $[6,10$, 11]. Although theirs changes do not remove pores fully [12].

In the present work is shown that scanning speed reducing leads to porosity decrease and thus corrosion rate each of initial state and all treatment of AISI 321 SL-melted steel is lowered.

Pores influence on corrosion resistance of machining specimens was evaluated by relative corrosion rate (RCR). The relative corrosion rate is the ratio of the corrosion rate of samples $\mathrm{B}$ to the corrosion rate of samples A. Figure 5 shows correlation between porosity and RCR. AISI 321 specimens have RCR less 1 and this means that surface machining increases corrosion resistance. RCR of AISI $316 \mathrm{~L}$ is more than 1 and therefore surface treatment has an adverse effect in this case.

Additional processing using has a different influence on corrosion resistance of AISI 321 and AISI 316L. Surface machining of SL-melted AISI 316L resulted to corrosion loos increasing. Heat treatment and following machining using improved corrosion behaviour. Similar correlation is observed for AISI 321 obtained by 600 $\mathrm{mm} / \mathrm{s}$. Manufactured by 650 and $750 \mathrm{~mm} / \mathrm{s}$ specimens have least corrosion rate after machining, austenitization leads to pitting corrosion susceptibility increasing. The contradiction with another works reported heat treatment positive influence on corrosion resistance of stainless steels due to residual stresses reduce, segregation removal [7] can explain at first cold working layer presence and second mass loss measurement error due to difficult removing of product corrosion from subsurface pitting.

Though AISI 316L specimens obtained by $800 \mathrm{~mm} / \mathrm{s}$ have a maximum porosity its corrosion rate was lower comparison with SL-melted AISI 321. Taking account negative influence of pores corrosion resistance depends on stainless steel chemical composition. Therefore, alloying stainless steels with chromium, molybdenum and nitrogen [13] results to decrease of corrosion susceptibility. 


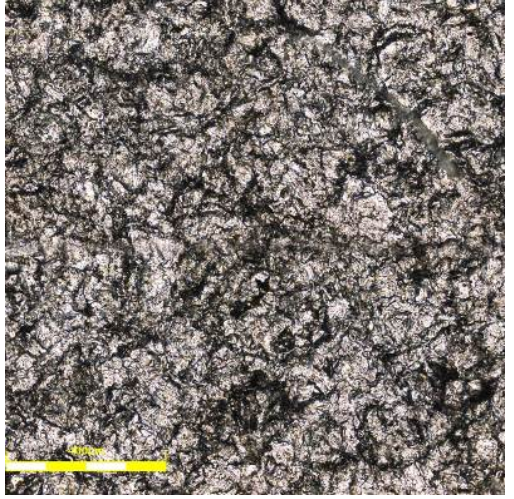

a)

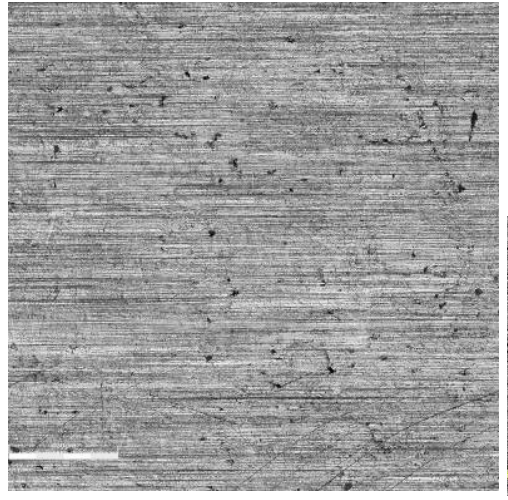

b)

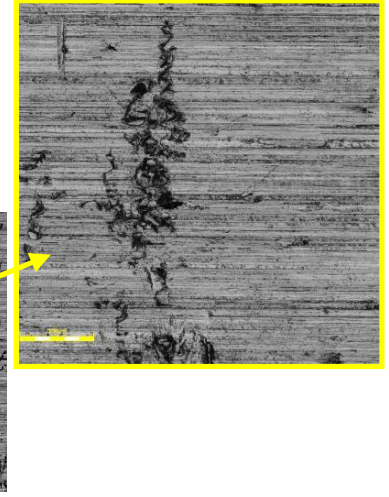

c)

Fig. 4. Surface view (by Olympus LEXT 4100) of SL-melted AISI 321 steel obtained by $650 \mathrm{~mm} / \mathrm{s}$ after: a) initial state (A); b) machining (B); c) austenitization and machining (C)

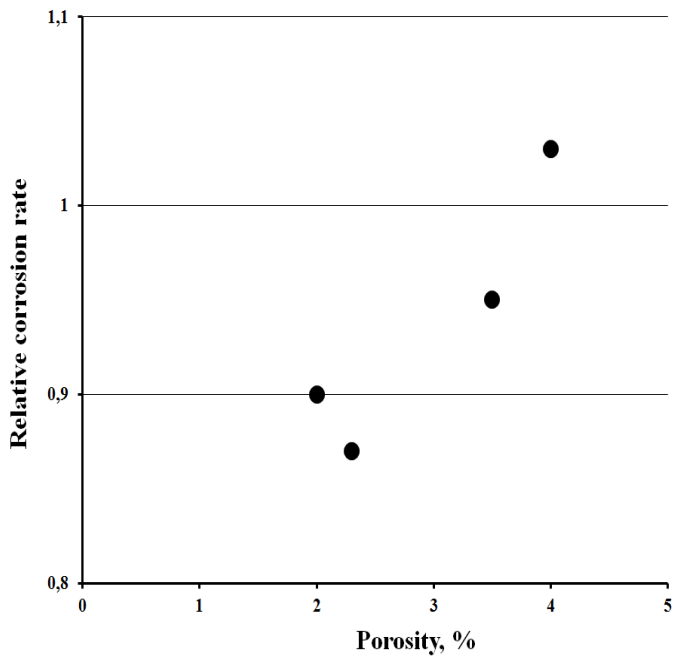

Fig. 5. Porosity influence on relative corrosion rate of machining stainless exposed in $10 \% \mathrm{FeCl}_{3} \cdot 6 \mathrm{H}_{2} \mathrm{O}$ at $60^{\circ} \mathrm{C}$ for $5 \mathrm{~h}$

\section{Conclusions}

1. It is recommended pitting corrosion resistance evaluation carries out according to corrosion mass loss and metallographic studies. Taking account aggressive corrosion environments $10 \% \mathrm{FeCl}_{3} \cdot 6 \mathrm{H}_{2} \mathrm{O}$ pits depth and density determine are necessary. Metallographic depth measurement can apply.

2. To ensure resistance to pitting corrosion of SLmelted stainless steels, it is necessary to introduce requirements for limiting porosity. Based on the data obtained with an increase in porosity of $1 \%$, the corrosion rate increases by $10 \%$ in the initial state, by $15 \%$ after machining and by $21 \%$ after austenization.

The study was supported by grant of Russian Scientific Fund № 15-19-00210.

\section{References}

1. Offshore Standards DNV-OS-F101-2000, STO Gazprom 2-3.7-050-2006 Submarine pipeline systems.
2. GOST R 54382-2011 Oil and gas industry. Submarine pipeline systems. General requirements.

3. A. Zhukov, A. Deev, P. Kuznetsov, Ph. Pr., 89 (2017)

4. E. Yasa, J-P. Kruth,, Proc. Eng. № 19, 2011

5. S. A. Khairallah, A. Anderson, J. Mat. Proc. Techn., (2014)

6. Y. Sun, A. Moroz, K. Alrbaey, J. Mater. Eng. Perform., 23, 2 (2014)

7. P. Ganesh, Raju Giri, R. Kaul, P. Ram Sankar, Pragya Tiwari, Ashok Atulkar, R.K. Porwal, R.K. Dayal, L.M. Kukreja, Mat. and Design, 39 (2012)

8. J.A. Cherry, H.M. Davies, S. Mehmood, N.P. Lavery, S.G.R. Brown, J. Sienz, Adv. Manuf. Tech., vol. 76 (2015)

9. P. Mercelis, J-P. Kruth, Rap. protot., 12/5 (2006)

10. I. Yadroitsev, I. Smurov, Ph.proc. 12 (2011)

11. M. Badrossamay, T.H.C. Childs, Mach. tools \& manuf., 47 (2007)

12. R. Li, J. Liu, Y. Shi, M.Du, Zh. Xie, J. Mat. Eng. Perform., vol. 19, 5 (2010)

13. ASM Handbook. Corrosion, 13, (1992) 